Article

\title{
Evidence of a Possible Viral Host Switch Event in an Avipoxvirus Isolated from an Endangered Northern Royal Albatross (Diomedea sanfordi)
}

\author{
Subir Sarker ${ }^{1, * \mathbb{D}}$, Timothy R. Bowden ${ }^{2,3}$ and David B. Boyle ${ }^{2}$ \\ 1 Department of Microbiology, Anatomy, Physiology and Pharmacology, School of Agriculture, Biomedicine \\ and Environment, La Trobe University, Melbourne, VIC 3086, Australia \\ 2 CSIRO Livestock Industries, Australian Animal Health Laboratory, Geelong, VIC 3220, Australia; \\ timothy.bowden@csiro.au (T.R.B.); davidboyle48@gmail.com (D.B.B.) \\ 3 CSIRO Australian Animal Health Laboratory, Australian Centre for Disease Preparedness, \\ Geelong, VIC 3220, Australia \\ * Correspondence: s.sarker@latrobe.edu.au; Tel.: +61-394-792-317; Fax: +61-394-791-222
}

Citation: Sarker, S.; Bowden, T.R. Boyle, D.B. Evidence of a Possible Viral Host Switch Event in an Avipoxvirus Isolated from an Endangered Northern Royal Albatross (Diomedea sanfordi). Viruses 2022, 14, 302. https://doi.org/ $10.3390 / \mathrm{v} 14020302$

Academic Editor: Jônatas Abrahão

Received: 22 December 2021

Accepted: 1 February 2022

Published: 1 February 2022

Publisher's Note: MDPI stays neutral with regard to jurisdictional claims in published maps and institutional affiliations.

Copyright: (C) 2022 by the authors. Licensee MDPI, Basel, Switzerland. This article is an open access article distributed under the terms and conditions of the Creative Commons Attribution (CC BY) license (https:// creativecommons.org/licenses/by/ $4.0 /)$.

\begin{abstract}
Avipoxviruses have been characterized from many avian species. Two recent studies have reported avipoxvirus-like viruses with varying pathogenicity in reptiles. Avipoxviruses are considered to be restricted to avian hosts. However, reports of avipoxvirus-like viruses from reptiles such as the green sea turtle (Chelonia mydas) and crocodile tegu (Crocodilurus amazonicus) suggest that cross-species transmission, within avian species and beyond, may be possible. Here we report evidence for a possible host switching event with a fowlpox-like virus recovered from an endangered northern royal albatross (Diomodea sanfordi)—a species of Procellariiformes, unrelated to Galliformes, not previously known to have been infected with fowlpox-like viruses. Complete genome sequencing of this virus, tentatively designated albatrosspox virus 2 (ALPV2), contained many fowlpox viruslike genes, but also 63 unique genes that are not reported in any other poxvirus. The ALPV2 genome contained 296 predicted genes homologous to different avipoxviruses, 260 of which were homologous to an American strain of fowlpox virus (FWPV). Subsequent phylogenetic analyses indicate that ALPV2 likely originated from a fowlpox virus-like progenitor. These findings highlight the importance of host-switching events where viruses cross species barriers with the risk of disease in close and distantly related host populations.
\end{abstract}

Keywords: avipoxvirus; host-switch; evolution; northern royal albatross

\section{Introduction}

Over the past several decades, marine bird populations have been decreasing globally [1] with the sustainability of the albatrosses (family Diomedeidae) and large petrels (Macronectes and Procellaria spp.) being under significant threat [2-4]. One of the world's largest seabirds, the northern royal albatross (Diomedea sanfordi) is categorized as an "endangered" species under the International Union for Conservation of Nature (IUCN) Red List and is classified as Category B for management urgency [5]. Northern royal albatrosses range extensively throughout the Southern Ocean, yet infrequently into Antarctic waters. Breeding colonies are confined to the Chatham Islands and Taiaroa Head on the Otago Peninsula, Dunedin, New Zealand. The overall breeding population in the Chatham Islands colonies (99\% of the total) is anticipated at about 6500-7000 pairs, which equates to a total population of approximately 17,000 adults [6].

Human activities, including commercial fishing and pollution, are recognized as threats for incidental mortality of these species [5,7-11]. Invasive alien species, degradation or destruction of nesting grounds, storms and flooding, pollution of the marine environment, and ingestion of plastics are additional factors contributing to population 
declines [5,12]. Infectious diseases, including those caused by avipoxviruses, are also recognized as potential threats to the preservation of small and endangered bird populations, including albatrosses [13-18]. Population declines in multiple species from the avifauna of Hawaii have been attributed to the introduction of avipoxviruses [19]. Avipoxviruses have also been identified as an ongoing threat to birds on the Galapagos Islands [20]. In contrast, despite the severity of avipoxvirus infections in some chicks, the high recovery rate, fledgling success, and post-fledgling survival observed in Hawaiian Laysan albatrosses (Phoebastria immutabilis), even in years of high rainfall when the prevalence of infections in chicks averaged as high as $88 \%$, suggested that this particular albatross species has good immunity to avian poxviruses [21].

Avipoxviruses are large, double-stranded DNA (dsDNA) viruses belonging to the genus Avipoxvirus in the subfamily Chordopoxvirinae, family Poxviridae. Avipoxviruses have been detected in at least 374 avian species from 23 orders of wild and domestic avifauna worldwide [22-25]. Strikingly, recent studies have discovered two avipoxviruslike viruses of varying pathogenicity in reptiles [26,27]. Sarker et al. [26] reported the presence of a novel avipoxvirus-like virus, cheloniid poxvirus 1 (ChePV-1), from an endangered green sea turtle (Chelonia mydas). ChePV-1, characterized microscopically and genetically from a cutaneous lesion, was shown to be considerably different from other known poxviruses but showed the greatest sequence identity (89.3\%) to an avipoxvirus (shearwater poxvirus 2 (SWPV2)). Another recent study characterized a novel poxvirus, teiidaepox virus 1 (TePV-1), in cutaneous tissue of a lizard species, crocodile tegu (Crocodilurus amazonicus), native to the Amazon and Orinoco basins of South America [27]. TePV-1 was also closely related genetically and phylogenetically to avipoxviruses, and showed the highest amino acid sequence identities to flamingopox virus $(74.3 \%)$ and fowlpox virus $(76.0 \%)$ using the DNA polymerase and DNA topoisomerase genes, respectively [27]. The authors highlighted a possible virus transmission event between avian and reptilian species [27]. In addition, evidence of an avipoxvirus infection was reported in a critically ill rhinoceros in 1969, and this was characterized as an atypical fowlpox virus [28], although genome sequence data of the virus have not been reported.

Herein we report the genomic characterization of a second novel avipoxvirus, ALPV2, isolated from a skin lesion collected from an endangered northern royal albatross on the Otago Peninsula, New Zealand. In contrast to the previously reported ALPV isolate from this region [29], and considering that the northern royal albatross (Diomedea sanfordi) is a species of Procellariiformes unrelated to Galliformes, we provide evidence that ALPV2 represents a possible host switch event with a fowlpox virus-like progenitor.

\section{Materials and Methods}

\subsection{Sampling, Virus Isolation and Genome Sequencing}

Cutaneous pox lesions were collected from an endangered juvenile northern royal albatross (Diomedea sanfordi), located on the Otago Peninsula, near Dunedin, on the South Island of New Zealand. Sampling was conducted in March 1997 by Wallaceville Animal Research Centre, New Zealand, and lesions were sent to the Australian Animal Health Laboratory, Geelong, Victoria, Australia (sample ID: TST 08/05/1997). Virus isolation and propagation, as well as DNA extraction and genome sequencing, were subsequently undertaken as described previously [29].

\subsection{Genome Assembly and Annotation}

The resulting 3,374,936 paired-end raw sequence reads were used to assemble the complete genome of ALPV2, using CLC Genomics Workbench (version 9.5.4, CLC bio, a QIAGEN Company, Prismet, Aarhus C, Denmark) and Geneious (version 10.2.2, Biomatters, New Zealand), as described previously [29-33]. This resulted in the generation of a 286,155 bp genome. Clean raw reads (2.38 million) were mapped back to the assembled ALPV2 genome resulting in an average coverage of 668.55x. The genome was annotated according to the previously published protocol [18] using Geneious software (version 10.2.2, 
Biomatters, New Zealand). Open reading frames (ORFs) longer than 30 amino acids, with a methionine start codon (ATG) and minimal overlap with other ORFs (not exceeding 50\% of one of the genes), were selected and annotated. ORFs shorter than 30 amino acids that had been previously annotated in other poxvirus genomes were also included. Similarity BLAST searches were performed on the predicted ORFs and were annotated as potential genes if predicted ORFs showed significant sequence similarity to known viral or cellular genes (BLAST E value $\leq \mathrm{e}^{-5}$ ) [34].

To predict the function of putative unique ORFs identified in this study, the derived protein sequence of each ORF was searched using multiple applications to identify conserved domains or motifs. Transmembrane helices were searched using the TMHMM package (version 2.0) [35] and TMpred [36]. Additionally, searches for conserved secondary structure (HHpred) [37] and protein homologs were conducted using Phyre2 [38] and SWISS-MODEL [39].

\subsection{Comparative Genomics}

Genomic features of the newly sequenced ALPV2 were visualised using Geneious (version 10.2.2). Sequence similarity percentages between representative Chordopoxvirus (ChPV) and ALPV2 complete genome sequences were determined using tools available in Geneious (version 10.2.2). Dot plots were created based on the EMBOSS dottup program in Geneious software, with word size $=12$ [40].

\subsection{Phylogenetic Analyses}

Phylogenetic analyses were performed using the ALPV2 genome sequence determined in this study, together with other selected ChPV genome sequences available in GenBank (Table 1). Nucleotide sequences of the partial DNA polymerase and partial p4b genes, as well as concatenated amino acid sequences of nine poxvirus core proteins, were aligned as described previously [41] using the MAFTT L-INS-I algorithm implemented in Geneious (version 7.388) [42]. To determine the best-fit model to construct phylogenetic analyses, a model test was performed using CLC Genomics Workbench (version 9.5.4), which favoured a general-time-reversible model with gamma distribution rate variation and a proportion of invariable sites (GTR+G+I). Phylogenetic analyses for nucleotide sequences were performed under the GTR substitution model, but the WAG substitution model was chosen for concatenated amino acid sequences with 1000 bootstrap replicates in CLC Genomic Workbench (version 9.5.4). 
Table 1. Related poxvirus genome sequences used in further analysis of ALPV2.

\begin{tabular}{|c|c|c|c|c|}
\hline Virus & Abbreviation & Year of Isolation & GenBank Accession Number & Reference \\
\hline Albatrosspox virus 2 & ALPV2 & 1997 & OK348853 & This study \\
\hline Albatrosspox virus & ALPV & 1997 & MW365933 & [29] \\
\hline Canarypox virus & CNPV & 1948,2015 & AY318871, MG760432 & {$[43,44]$} \\
\hline Cheloniidpox virus 1 & ChePV1 & 2018 & MT799800 & [26] \\
\hline Fowlpox virus & FWPV & $\begin{array}{l}2012,2000 *, 2010 *, 2015 \\
2016,2018 *, 2011 *, 2018 \\
2010 \#\end{array}$ & $\begin{array}{l}\text { MW142017, AF198100*, } \\
\text { AJ581527 *, MH734528, } \\
\text { MH719203, MF766430-32, } \\
\text { MH709124-25 *, MG702259 *, } \\
\text { OK558608-09, KX196452 \# }\end{array}$ & [45-49] \\
\hline Flamingopox virus & FGPV & 2008 & MF678796 & [24] \\
\hline Magpiepox virus & MPPV & 2018 & MK903864 & [32] \\
\hline Magpiepox virus 2 & MPPV2 & 1956 & MW485973 & {$[50]$} \\
\hline Mudlarkpox virus & MLPV & 2019 & MT978051 & [41] \\
\hline Penguinpox virus & PEPV & 1992 & KJ859677 & [51] \\
\hline Penguinpox virus 2 & PEPV2 & 1997 & MW296038 & [18] \\
\hline Pigeonpox virus & $\mathrm{FeP} 2$ & 1992 & KJ801920 & [51] \\
\hline Saltwater crocodilepox virus 1 & SwCRV1 & 2017 & MG450915 & {$[52,53]$} \\
\hline Shearwaterpox virus 1 & SWPV1 & 2015 & KX857216 & {$[30]$} \\
\hline Shearwaterpox virus 2 & SWPV2 & 2015 & KX857215 & {$[30]$} \\
\hline Turkeypox virus & TKPV & 2011 & NC_028238 & [54] \\
\hline Teiidae poxvirus 1 & TePV-1 & 2019 & MT712273 & [27] \\
\hline
\end{tabular}

* = year of submission to GenBank; ${ }^{*}$ = unpublished.

\section{Results}

\subsection{Genome of Albatrosspox Virus 2 (ALPV2)}

We determined the complete genome sequence of ALPV2 as a linear double-stranded DNA molecule 286,155 bp in length (GenBank OK348853). The ALPV2 genome encompassed a large central coding region surrounded by two matching inverted terminal repeat (ITR) regions, constituting 7781 bp each (coordinates 1-7781 sense and 278,375-298,392 antisense orientation) similar to other characterized avipoxviruses [30-32,41,45,51]. The ALPV2 genome showed the highest nucleotide identity (99.3\%) with an American virulent strain of fowlpox virus isolated in 1999 (GenBank accession no. AF198100.1) [45] (Table 2), followed by PEPV (76.6\%), FGPV (75.0\%), and FeP2 (73.1\%). However, the ALPV2 genome showed much lower nucleotide identity (48.8\%) with the only other reported albatrosspox virus (ALPV), which had also been collected in March 1997 from a northern royal albatross on the Otago Peninsula, New Zealand [29]. The A+T content of the ALPV2 genome was $69.1 \%$, which was comparable to other sequenced avipoxviruses (Table 2). 
Table 2. Comparative analysis of representative avipoxviruses and ALPV2 based on complete genome nucleotide sequences.

\begin{tabular}{|c|c|c|c|c|c|c|}
\hline Avipoxvirus (Abbreviation) & $\begin{array}{c}\text { GenBank } \\
\text { Accession Number }\end{array}$ & $\begin{array}{c}\text { Genome } \\
\text { Identity (\%) }\end{array}$ & $\begin{array}{c}\text { Genome } \\
\text { Length (kbp) }\end{array}$ & $\begin{array}{c}A+T \\
\text { Content (\%) }\end{array}$ & $\begin{array}{l}\text { Number } \\
\text { of ORFs }\end{array}$ & Reference \\
\hline Albatrosspox virus 2 (ALPV2) & OK348853 & & 286 & 69.1 & 359 & This study \\
\hline Albatrosspox virus (ALPV) & MW365933 & 48.8 & 352 & 71.2 & 336 & [29] \\
\hline Canarypox virus (CNPV) & AY318871 & 48.0 & 360 & 69.6 & 328 & [43] \\
\hline Fowlpox virus (FWPV) & AF198100 & 99.3 & 289 & 69.1 & 260 & [45] \\
\hline Flamingopox virus (FGPV) & MF678796 & 75.0 & 293 & 70.5 & 285 & [24] \\
\hline Magpiepox virus (MPPV) & MK903864 & 51.1 & 293 & 70.4 & 301 & [32] \\
\hline Magpiepox virus 2 (MPPV2) & MW485973 & 50.8 & 298 & 70.5 & 419 & [50] \\
\hline Mudlarkpox virus (MLPV) & MT978051 & 49.0 & 343 & 70.2 & 352 & [41] \\
\hline Penguinpox virus (PEPV) & KJ859677 & 76.6 & 307 & 70.5 & 285 & [51] \\
\hline Penguinpox virus 2 (PEPV2) & MW296038 & 49.0 & 350 & 69.9 & 327 & [18] \\
\hline Pigeonpox virus (FeP2) & KJ801920 & 73.1 & 282 & 70.5 & 271 & [51] \\
\hline Shearwaterpox virus 1 (SWPV1) & KX857216 & 52.2 & 327 & 72.4 & 310 & [30] \\
\hline Shearwaterpox virus 2 (SWPV2) & KX857215 & 48.4 & 351 & 69.8 & 312 & [30] \\
\hline Turkeypox virus (TKPV) & KP728110 & 40.3 & 189 & 70.2 & 171 & [54] \\
\hline
\end{tabular}

\subsection{Genome Annotation and Comparative Analyses of ALPV2}

The ALPV2 genome contained 359 predicted open reading frames (ORFs) encoding proteins ranging from 30 to 1918 amino acids in length. Putative genes were numbered from left to right (Figure 1 and Supplementary Table S1). Among them, 16 predicted ORFs were located within the ITRs and were thus present as diploid copies. Comparative analysis of the predicted ORF sequences was conducted, and 298 of the ORFs had greatest similarity with other ChPV gene products (E value $\leq 10^{-5}$ ) (Figure 1 and Supplementary Table S1). Among these predicted genes, 260 showed the highest similarity to an American strain of fowlpox virus (FWPV) [45]. A further twenty (ORF-006, -039, -57, -74, -75, -144, -154, -160, $-208,-216,-217,-222,-244,-274,-275,-287,-327,-331,-332$ and -354$)$ showed highest similarity to fowlpox virus vaccine strain (FWPV-S) [48], two (ORF-056 and -260) to FWPV strain FP9 [55], one (ORF-125) to FWPV strain HP440 [56], two (ORF-007 and -353) to MLPV [41], two (ORF-020, -318) to FGPV [24], two (ORF-026 and -103) to PEPV [51], two (ORF-172 and- 299) to CNPV [43] and one (ORF-037) to FeP2 [51] (Figure 1 and Supplementary Table S1). In comparison to FWPV, none of the genes were absent in the ALPV2 genome, and a further four ORFs (ORF-231, -232, 342 and -343) were truncated and or fragmented (Figure 1 and Supplementary Table S1). Two fragmented ORFs of ALPV2 (ORF-231 and -232) are conserved chordopoxvirus genes, whereas the other two (ORF-342 and -343) are non-conserved genes. Additional studies will be needed to determine whether fragmented ORFs are expressed and functional.

Remarkably, ALPV2 contained 63 predicted protein-coding genes that were not present in any other poxvirus, nor did they match any sequences in the NR protein database using BLASTX and BLASTP [34]. These unique ORFs' encoded proteins of 30 to 48 amino acids in length (Figure 1 and Supplementary Table S1). Among them, 21 unique ALPV2 proteincoding ORFs (ORF-016, -019, -030, -050, -052, -066, -088, -107, -132, -156, -157, -162, -213, -219, $-224,-225,-288,-311,-323,-340,-344)$ were predicted to contain a single transmembrane helix, and a further two (ORF-024 and -031) were predicted to contain two transmembrane helices using the software packages employed in this study (Supplementary Table S1). However, we did not find any significant homology with known proteins for the unique ORFs encoded in the ALPV2 genome when using the Phyre2, HHpred and SWISS-MODEL, which might be due to the lack of closely related structures in these databases. 


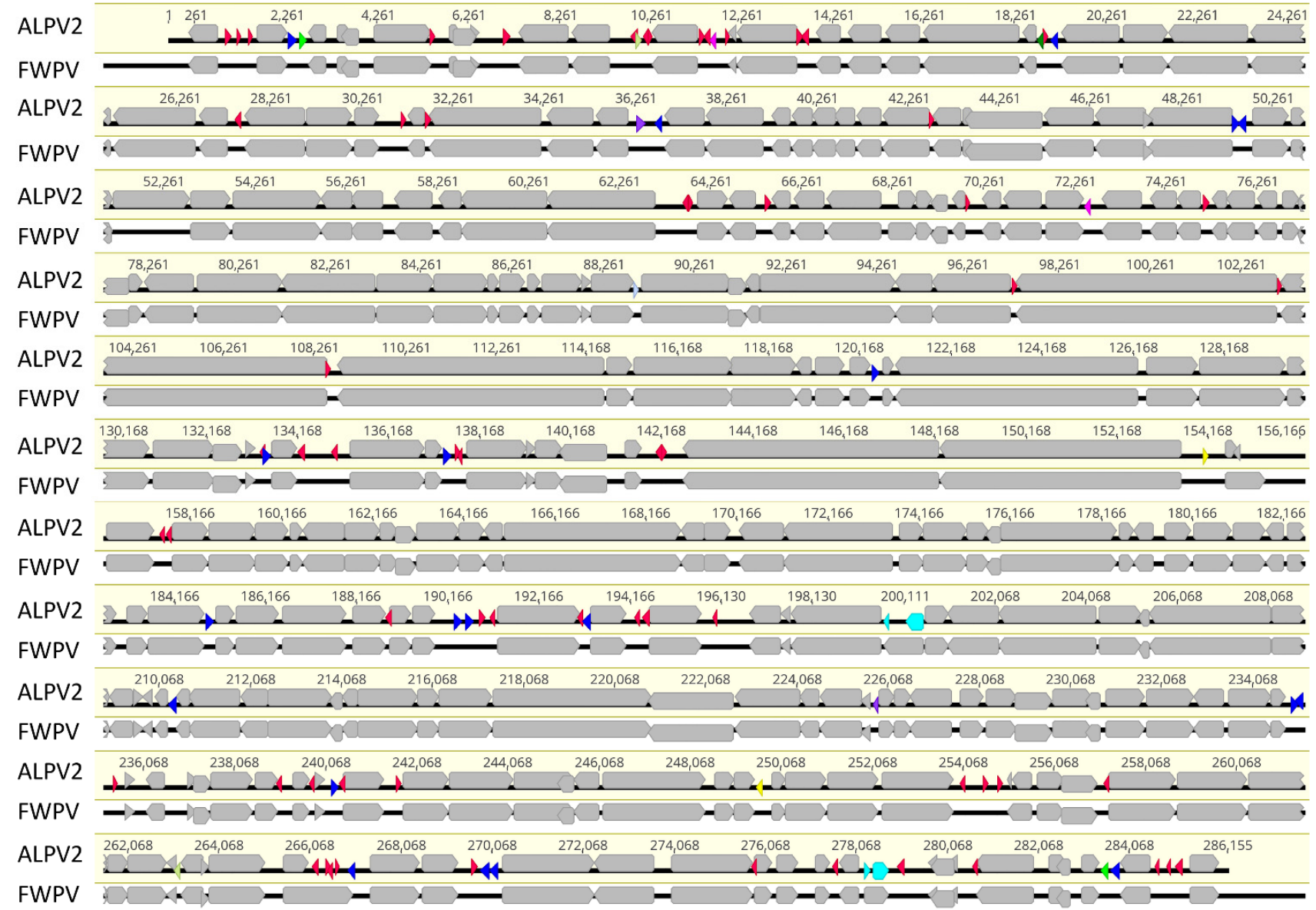

Intact ORF of ALPV2 syntenic with FWPV-American strain $\square$ Identity to FWPV-S strain Identity to FWPV-FP9 strain

Identity to MLPV ORF Identity to CNPV ORF Identity to PEPV ORF Fragmented ORF compared to FWPV

Identity to FGPV ORF Identity to FWPV-HP440 strain Identity to FeP2 ORF Possible unique ORF

Figure 1. Genomic illustration of ALPV2. The arrows depict the direction of transcription of genes and open reading frames (ORFs). Each gene or ORF is color coded, as indicated by the key in the legend.

Comparison of the ALPV2 genome with those of other avipoxviruses was performed using dot plot analyses. The ALPV2 genome was highly syntenic with FWPV, PEPV, FGPV and FeP2 (Figure 2A-D). Moreover, differences in synteny with FGPV and FeP2 were observed (Figure 2C-D, highlighted as black arrows), mainly due to the presence of two large additional copies of variola B22R gene family proteins in ALPV2 (ORF-170 and -171, 1870 and 1766 amino acids in length, respectively). The ALPV2 genome also demonstrated significant differences in the entire genome compared to ALPV, SWPV1, CNPV and TKPV (Figure 2E-H). Within these highlighted regions (orange arrows), multiple SNPs and insertions/deletions (indels) accounted for the variation observed between the genomes (Figure 2E-H). 

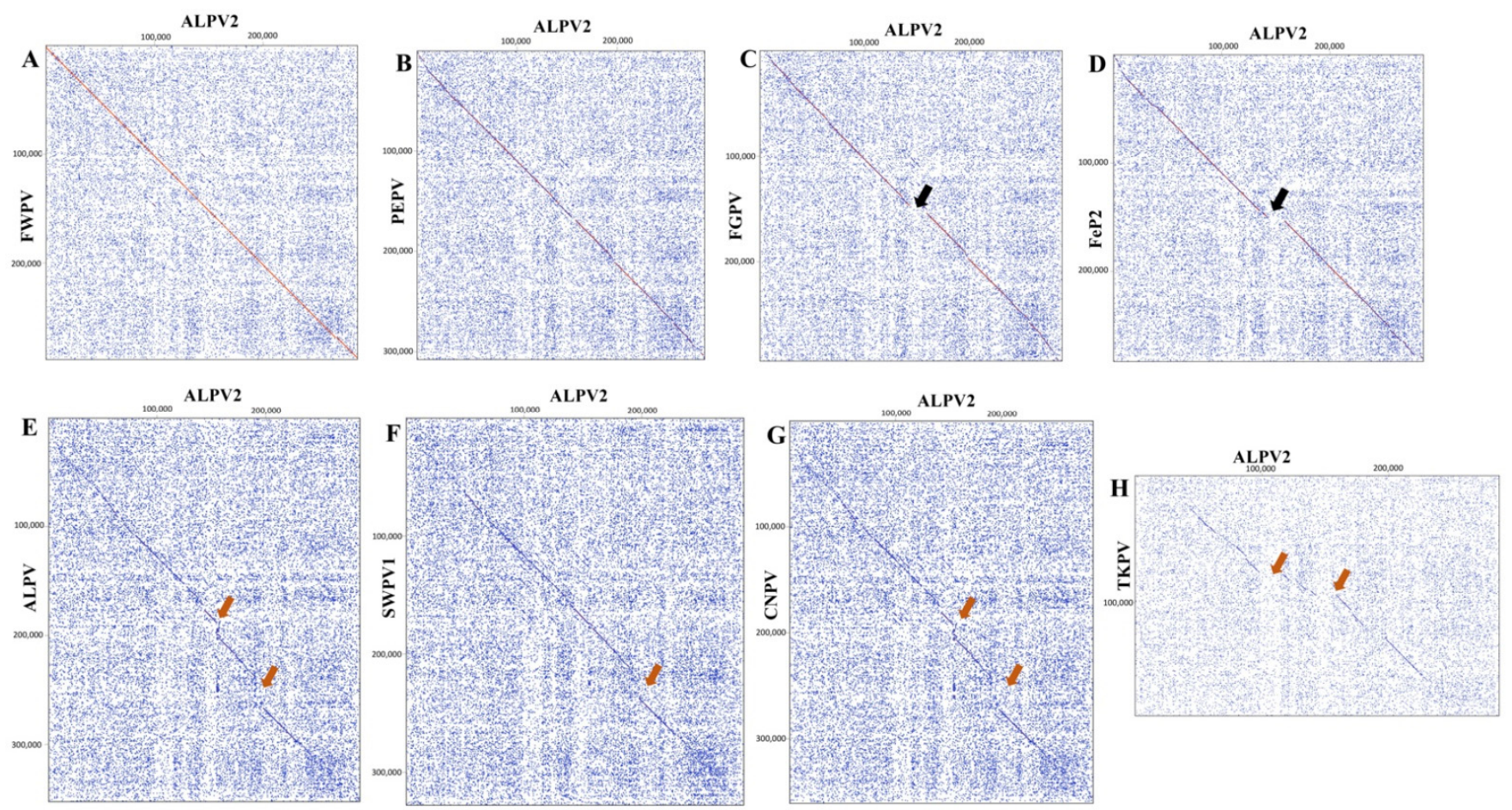

Figure 2. Dot plots of the ALPV2 genome ( $x$-axis) versus other poxvirus genomes ( $y$-axis). (A) ALPV2 vs. FWPV; (B) ALPV2 vs. PEPV; (C) ALPV2 vs. FGPV; (D) ALPV2 vs. FeP2; (E) ALPV2 vs. ALPV; (F) ALPV2 vs. SWPV1; (G) ALPV2 vs. CNPV; and (H) ALPV2 vs. TKPV (refer to Table 1 for virus details and GenBank accession numbers). The Classic color scheme was chosen in Geneious (version 10.2.2) for the dot plot lines according to the length of the match, from blue for short matches to red for matches over $100 \mathrm{bp}$ long. Window size $=12$.

\subsection{Core/Conserved ORFs}

Similarly to other ChPVs, the ALPV2 genome contained 87 conserved core genes, which are involved in essential functions such as replication, transcription and virion assembly (Supplementary Table S1; highlighted with bold and italic font). The number of conserved ChPV genes is considered to range between 83-90 [24,51,57,58], which is consistent with the findings in the ALPV2 genome. Among them, two of the predicted ORFs, encoding immunodominant virion proteins ALPV-231 and -232, were truncated compared to FWPV168, which may warrant further studies to determine whether they are expressed and functional. Based on a recent study by Carulei et al. [24], we also searched for a further 47 genes that are conserved in avipoxviruses (Table 3). The ALPV2 genome was also predicted to contain these 47 conserved ORFs (Table 3), and none of the genes were found to be truncated or fragmented compared to a closely related fowlpox virus (FWPV) [45].

\subsection{Multigene Families}

Avipoxviruses are the largest ChPVs and contain several, large, multigene families with immune related functions comprising up to $50 \%$ of the genome [24,51]. Table 4 shows the copy numbers of each of the 14 multigene families identified in the ALPV2 genome compared with the other selected sequenced avian poxvirus genomes, including the recently characterized genomes of ALPV, MPPV2 and PEPV2. ALPV2 has a similar complement of multigene families compared to FWPV (total of 95 and 89 gene copies, respectively). However, ALPV2 has a significantly lower number of multigene families in comparison with ALPV (GenBank accession no. MW365933.1) (total of 95 and 139 gene copies, respectively). The copy number of ankyrin repeat, N1R/p28, C-type lectin and TGF- $\beta$ family genes were significantly higher in the ALPV2 genome compared to ALPV. 
Table 3. 47 ORFs found to be uniquely conserved in the selected fully sequenced avian poxvirus genomes.

\begin{tabular}{|c|c|c|c|c|c|c|c|c|c|c|c|}
\hline ALPV2 & FWPV & MPPV2 & MPPV & SWPV2 & SWPV1 & CNPV & PEPV & FeP2 & FGPV & TKPV & Function \\
\hline 33 & 16 & 44 & 34 & 28 & 24 & 32 & 19 & 19 & 11 & 001.1a & Ig-like domain \\
\hline 34 & 17 & 45 & 35 & 29 & 25 & 33 & 20 & 20 & 12 & 2 & V-type Ig domain \\
\hline 40 & 20 & 53 & 41 & 34 & 28 & 38 & 24 & 24 & 17 & 5 & C4L/C10L protein \\
\hline 41 & 21 & 54 & 42 & 35 & 29 & 39 & 25 & 25 & 18 & 6 & GPCR \\
\hline 42 & 22 & 55 & 43 & 36 & 30 & 40 & 26 & 26 & 19 & 7 & Ankyrin repeat \\
\hline 43 & 23 & 57 & 44 & 37 & 31 & 41 & 27 & 27 & 20 & 8 & Ankyrin repeat \\
\hline 44 & 24 & 58 & 45 & 38 & 32 & 42 & 28 & 28 & 21 & 9 & Ankyrin repeat \\
\hline 53 & 30 & 66 & 52 & 44 & 38 & 48 & 35 & 35 & 29 & 12 & Alkaline phosphodiesterase \\
\hline 54 & 31 & 69 & 55 & 46 & 40 & 50 & 36 & 36 & 30 & 13 & Ankyrin repeat \\
\hline 60 & 35 & 72 & 58 & 49 & 44 & 53 & 40 & 38 & 34 & 16 & Hypothetical protein \\
\hline 62 & 37 & 74 & 60 & 51 & 46 & 55 & 41 & 39 & 36 & 17 & Hypothetical protein \\
\hline 64 & 39 & 77 & 63 & 54 & 49 & 58 & 43 & 41 & 38 & 20 & B-cell lymphoma 2 (Bcl-2) \\
\hline 65 & 40 & 78 & 64 & 55 & 50 & 59 & 44 & 42 & 39 & 21 & Serpin \\
\hline 69 & 43 & 81 & 66 & 57 & 52 & 61 & 46 & 44 & 41 & 22 & DNA ligase \\
\hline 70 & 44 & 82 & 67 & 58 & 53 & 62 & 47 & 45 & 42 & 23 & Serpin family \\
\hline 71 & 46 & 83 & 68 & 59 & 54 & 63 & 48 & 46 & 43 & 24 & Hydroxysteroid dehydrogenase \\
\hline 73 & 47 & 87 & 71 & 61 & 56 & 65 & 49 & 47 & 44 & 25 & Semaphorin \\
\hline 76 & 48 & 92 & 75 & 64 & 59 & 68 & 50 & 48 & 45 & 26 & GNS1/SUR4 \\
\hline 82 & 54 & 103 & 83 & 72 & 66 & 76 & 56 & 54 & 51 & 32 & mutT motif \\
\hline 96 & 65 & - & - & 83 & 78 & 88 & 67 & 65 & 64 & 40 & Hypothetical protein \\
\hline 100 & 68 & 128 & 98 & 87 & 82 & 92 & 70 & 68 & 67 & 42 & Hypothetical protein \\
\hline 102 & 70 & 130 & 100 & 89 & 84 & 94 & 72 & 70 & 69 & 44 & T10-like protein \\
\hline 104 & 71 & - & 104 & 92 & 87 & 97 & 75 & 72 & 72 & 46 & Hypothetical protein \\
\hline 109 & 75 & 140 & 110 & 98 & 92 & 103 & 78 & 77 & 76 & 50 & $\mathrm{~N} 1 \mathrm{R} / \mathrm{p} 28$ \\
\hline 120 & 86 & 150 & 120 & 108 & 102 & 113 & 89 & 87 & 87 & 60 & Thymidine kinase \\
\hline 126 & 91 & 156 & 126 & 113 & 107 & 118 & 95 & 93 & 93 & 65 & Hypothetical protein \\
\hline 127 & 92 & 157 & 127 & 114 & 108 & 119 & 96 & 94 & 94 & 66 & Hypothetical virion core protein \\
\hline 142 & 104 & 169 & 139 & 126 & 120 & 131 & 108 & 106 & 106 & 75 & Hypothetical protein \\
\hline 143 & 105 & 170 & 140 & 127 & 121 & 132 & 109 & 107 & 107 & 76 & Hypothetical protein \\
\hline 149 & 110 & 175 & 145 & 132 & 126 & 137 & 114 & 112 & 112 & 80 & Hypothetical protein \\
\hline 152 & 113 & 178 & 148 & 135 & 129 & 140 & 117 & 115 & 115 & 83 & Hypothetical protein \\
\hline 196 & 145 & 243 & 199 & 179 & 167 & 191 & 153 & 146 & 151 & 109 & Hypothetical protein \\
\hline 203 & 151 & 253 & 209 & 187 & 175 & 199 & 159 & 153 & 157 & 113 & Deoxycytidine kinase \\
\hline 255 & 190 & 331 & 274 & 250 & 237 & 264 & 203 & 195 & 204 & 140 & A-type inclusion protein \\
\hline 256 & 191 & 333 & 275 & 251 & 238 & 265 & 204 & 196 & 205 & 141 & A-type inclusion protein \\
\hline 262 & 196 & 339 & 280 & 256 & 243 & 270 & 210 & 202 & 211 & 144 & Hypothetical protein \\
\hline 267 & 201 & 343 & 284 & 259 & 247 & 273 & 215 & 207 & 216 & 149 & Hypothetical protein \\
\hline 269 & 203 & 344 & 285 & 260 & 248 & 274 & 216 & 208 & 217 & 150 & Tyrosine kinase \\
\hline 271 & 205 & 346 & 287 & 262 & 250 & 276 & 218 & 210 & 219 & 151 & Hypothetical protein \\
\hline 273 & 207 & 348 & 289 & 264 & 252 & 278 & 220 & 212 & 221 & $151.1 \mathrm{a}$ & Hypothetical protein \\
\hline 277 & 208 & 351 & 292 & 267 & 255 & 281 & 222 & 214 & 224 & 152 & Hypothetical protein \\
\hline 280 & 211 & 355 & 296 & 271 & 259 & 285 & 225 & 216 & 227 & 153 & Epidermal Growth Factor \\
\hline 281 & 212 & 356 & 297 & 272 & 260 & 286 & 226 & 217 & 228 & 154 & Serine/threonine protein kinase \\
\hline 282 & 213 & 357 & 298 & 273 & 261 & 287 & 227 & 218 & 229 & 155 & Hypothetical protein \\
\hline 284 & 214 & 361 & 300 & 275 & 263 & 289 & 228 & 219 & 230 & 156 & Putative $13.7 \mathrm{kDa}$ protein \\
\hline 293 & 219 & 370 & 308 & 282 & 272 & 296 & 234 & 226 & 238 & 161 & Ankyrin repeat \\
\hline 312 & 232 & 394 & 327 & 290 & 283 & 304 & 248 & 238 & 251 & 164 & Ankyrin repeat \\
\hline
\end{tabular}


Table 4. Number of ORFs in each of the 14 multigene families identified in the fully sequenced avian poxvirus genomes.

\begin{tabular}{|c|c|c|c|c|c|c|c|c|c|c|c|c|c|c|c|}
\hline Gene Family & ALPV2 & ALPV & FWPV & MPPV2 & MPPV & PEPV2 & CNPV & SWPV2 & MLPV & SWPV1 & FP9 & PEPV & FeP2 & TKPV & FGPV \\
\hline Ankyrin Repeat & 33 & 48 & 31 & 78 & 62 & 49 & 51 & 46 & 47 & 50 & 22 & 33 & 26 & 16 & 45 \\
\hline B22R & 6 & 6 & 6 & 9 & 7 & 6 & 6 & 7 & 7 & 6 & 5 & 5 & 4 & 1 & 4 \\
\hline $\mathrm{N} 1 \mathrm{R} / \mathrm{p} 28$ & 12 & 28 & 10 & 20 & 24 & 24 & 26 & 20 & 25 & 20 & 8 & 11 & 11 & 3 & 13 \\
\hline C4L/C10L & 3 & 3 & 3 & 4 & 2 & 3 & 3 & 3 & 3 & 2 & 3 & 2 & 2 & 2 & 2 \\
\hline CC chemokine & 4 & 5 & 4 & 7 & 4 & 5 & 5 & 5 & 5 & 6 & 4 & 1 & 4 & 2 & 6 \\
\hline C-type lectin & 8 & 14 & 9 & 11 & 10 & 11 & 11 & 11 & 13 & 13 & 6 & 7 & 4 & 2 & 4 \\
\hline G protein-coupled receptor & 3 & 4 & 3 & 4 & 4 & 4 & 4 & 4 & 4 & 4 & 2 & 3 & 2 & 2 & 3 \\
\hline HT motif & 6 & 5 & 6 & 5 & 5 & 5 & 5 & 4 & 5 & 4 & 6 & 5 & 4 & 1 & 7 \\
\hline Ig-like domain & 6 & 9 & 5 & 13 & 10 & 9 & 9 & 8 & 8 & 9 & 4 & 6 & 4 & 3 & 9 \\
\hline Serpin & 6 & 5 & 5 & 5 & 5 & 5 & 5 & 5 & 5 & 5 & 5 & 4 & 4 & 3 & 5 \\
\hline $\mathrm{EFC}$ & 3 & 2 & 3 & 3 & 2 & 2 & 2 & 2 & 1 & 2 & 2 & 1 & 1 & 1 & 1 \\
\hline TGF- $\beta$ & 1 & 5 & 1 & 5 & 4 & 5 & 5 & 4 & 6 & 3 & 1 & 1 & 1 & 1 & 1 \\
\hline$\beta$-NGF & 2 & 2 & 2 & 2 & 2 & 2 & 2 & 2 & 2 & 2 & 2 & 0 & 0 & 2 & 3 \\
\hline IL-18 BP & 2 & 3 & 1 & 3 & 3 & 3 & 3 & 3 & 3 & 3 & 1 & 1 & 0 & 2 & 0 \\
\hline TOTAL & 95 & 139 & 89 & 169 & 144 & 133 & 137 & 124 & 134 & 129 & 71 & 80 & 67 & 41 & 103 \\
\hline
\end{tabular}

\subsection{Evolutionary Relationships of ALPV2}

Phylogenetic reconstruction using concatenated amino acid sequences of selected conserved ChPV genes provides clear evidence for the inclusion of ALPV2 in the genus Avipoxvirus. In the maximum likelihood (ML) tree (Figure 3), ALPV2 was located within a sub-clade A1 encompassing mostly FWPV isolates from chickens and wild turkeys with $100 \%$ bootstrap support. Using the same set of concatenated protein sequences, we found that the maximum inter-lineage sequence identity values ranged from $99 \%$ to $100 \%$ among FWPV isolates from chickens and turkeys, and ALPV2, respectively, which illustrated the phylogenetic position of this avipoxvirus sequenced from an endangered northern royal albatross, and further inferred that these viruses were likely derived from a common progenitor. Strikingly, a few other avipoxviruses were also positioned in the same A1 subclade when we used partial nucleotide sequences of the DNA polymerase and $\mathrm{p} 4 \mathrm{~b}$ genes (Figure 4). This included poxviruses isolated from birds of the order Galliformes (domestic fowl, Gallus domesticus; blue-eared pheasant, Crossoptilon auritum) in Hungary and Hawaii, respectively [59], and a Psittaciformes (superb parrot, Polytelis swainsonii) originating from Chile [59], which are almost identical to ALPV2 within this relatively small fragment of the genome. 


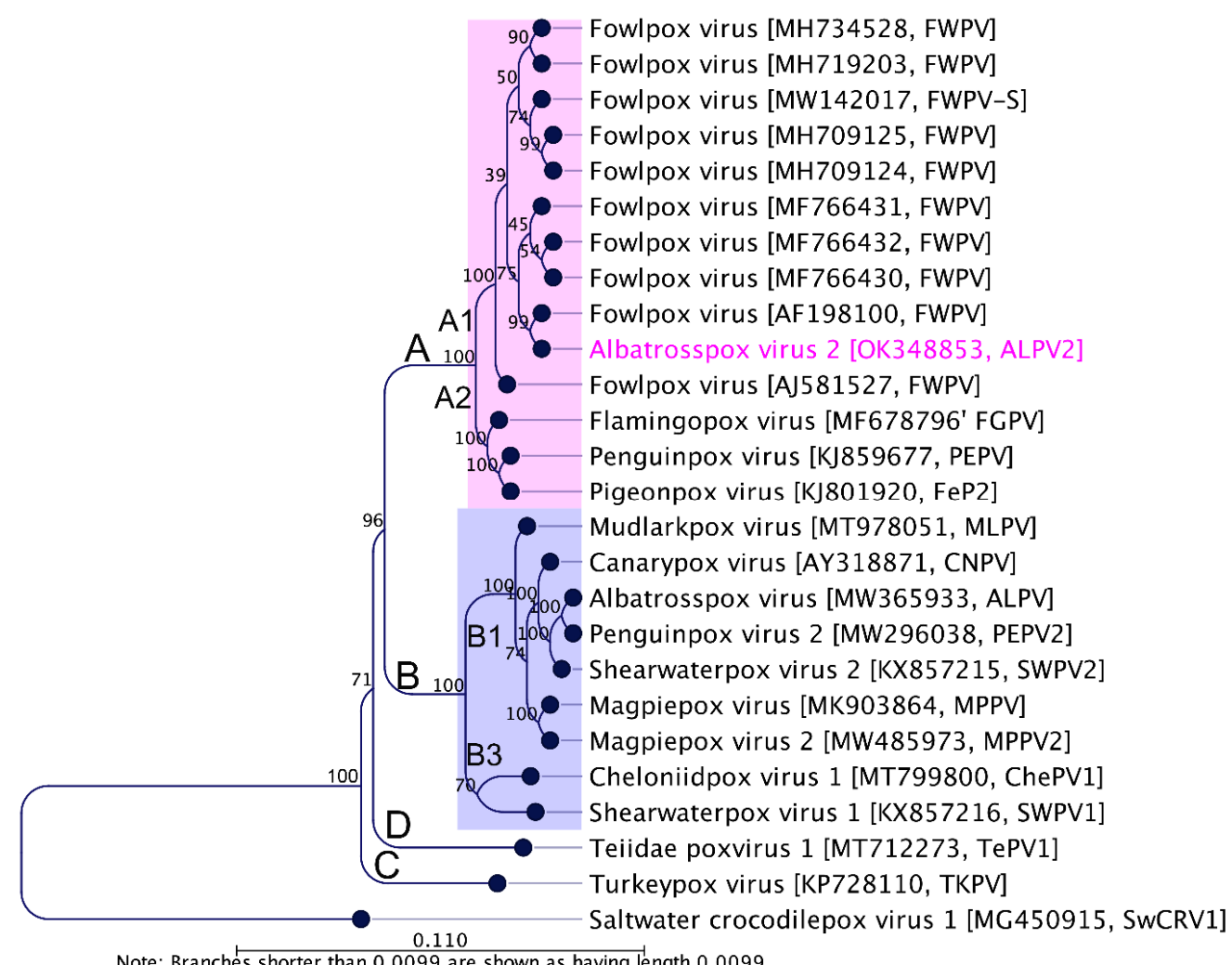

Figure 3. Phylogenetic relationships between ALPV2 and other chordopoxviruses. A maximum likelihood (ML) tree was constructed from multiple alignments of the concatenated amino acid sequences of the selected nine poxvirus core proteins using CLC Genomics Workbench (version 9.5.4). The numbers on the left show bootstrap values as percentages. The labels at branch tips refer to virus species, followed by GenBank accession numbers and abbreviated species names in parentheses. The position of ALPV2 is highlighted using pink text. Details of the poxviruses used in the phylogenetic tree are in Table 1. Saltwater crocodile poxvirus 1 (SwCRV1; MG450915) [53] was used as an outgroup. Major clades and sub-clades are designated according to Gyuranecz et al. (2013) [59].

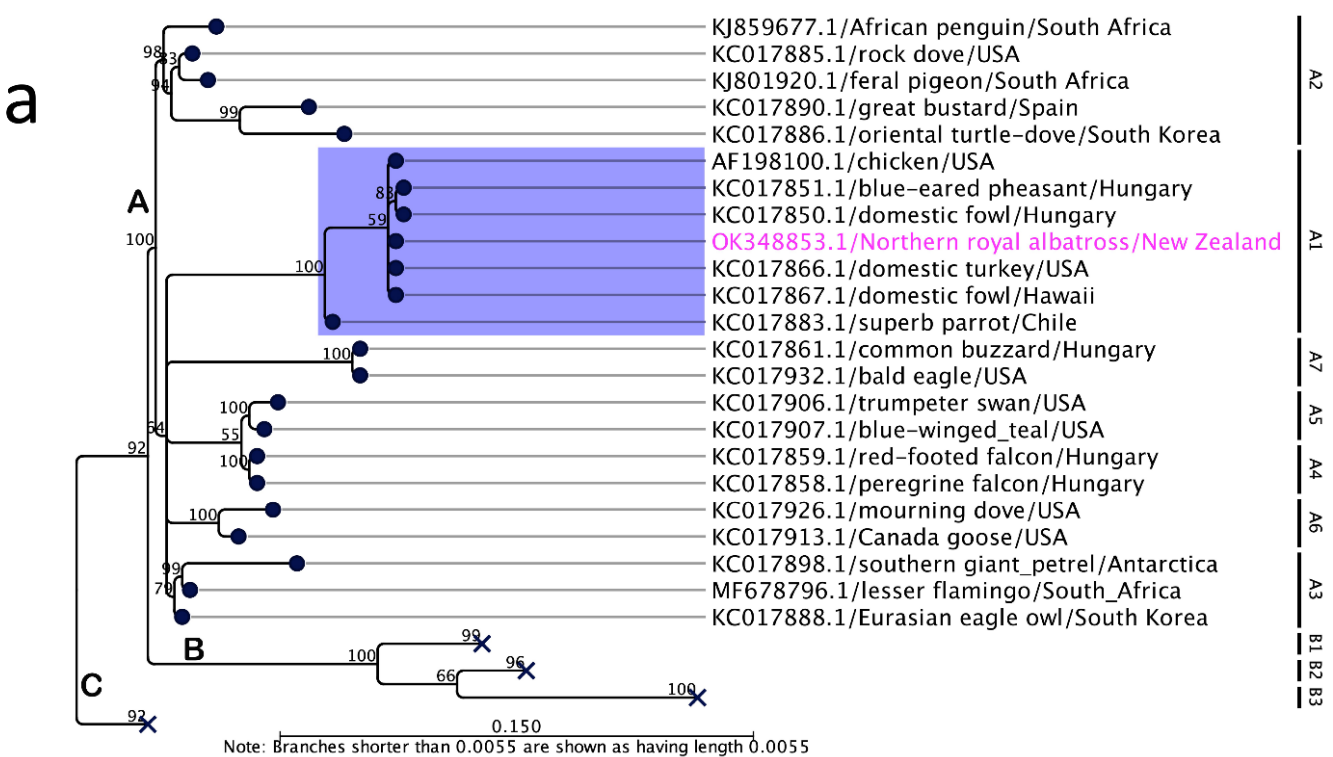

Figure 4. Cont. 


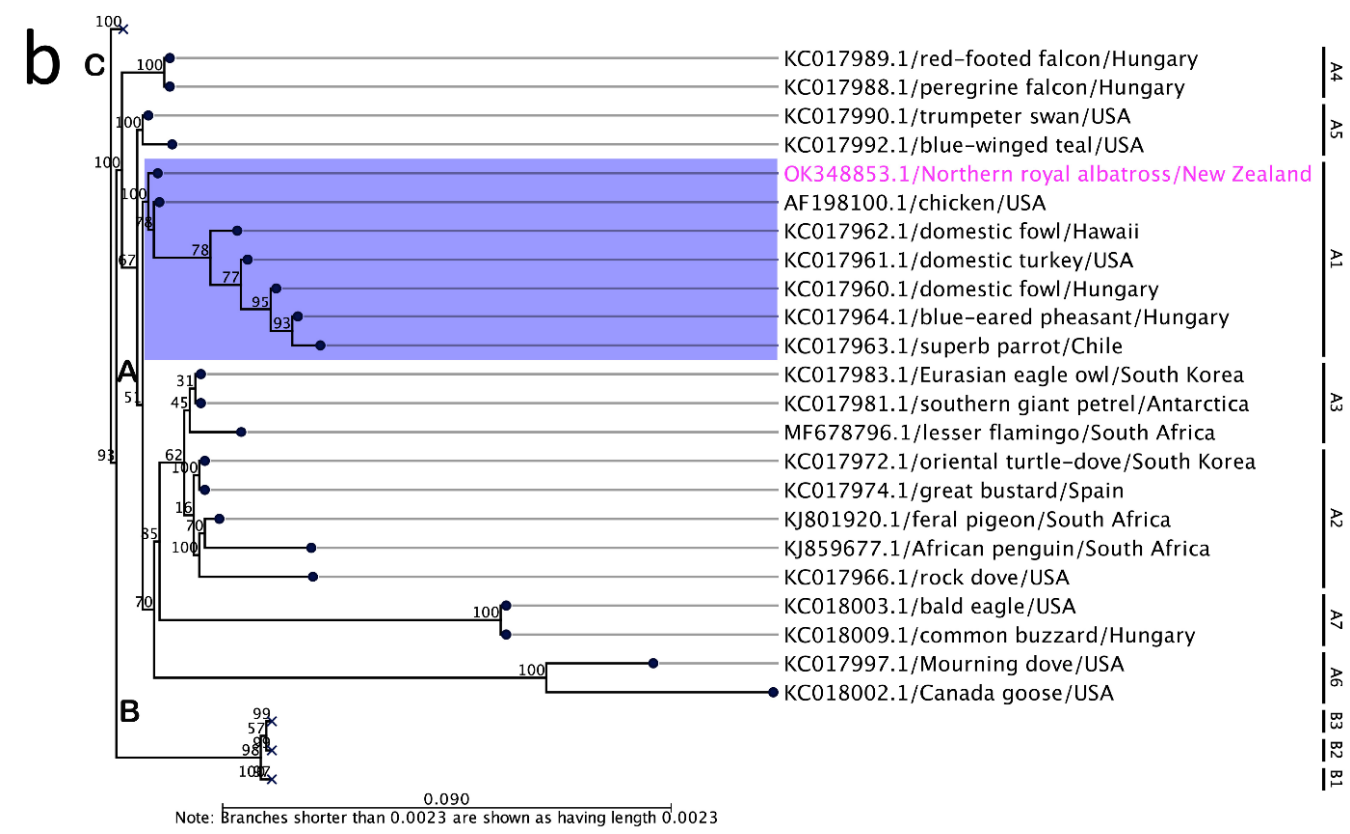

Figure 4. Maximum likelihood (ML) phylogenetic tree from partial nucleotide sequences of the DNA polymerase gene (a) and P4b gene (b) of selected avipoxviruses. Labels at branch tips refer to GenBank accession number/species/country of origin. The numbers on the left show bootstrap values as percentages. The relevant sub-clade A1 is highlighted using blue shading, whilst the position of ALPV2 is highlighted using pink text. The ML tree is displayed as a phylogram. The bootstrap value assigned to a node in the output tree is the percentage (0-100) of the bootstrap resamples which resulted in a tree containing the same subtree as that rooted at the node. Major clades and sub-clades are designated according to Gyuranecz et al. (2013) [59]. Major clades B and C in both the trees (a) and (b) are collapsed. For the complete ML phylograms, please see Supplementary Figures S1 and S2.

\section{Discussion}

We have documented a second avipoxvirus infection in a northern royal albatross, notably involving a possible host switch event. Applying various approaches for genomic comparison, ALPV2 was shown to be genetically similar to other avipoxviruses with the highest nucleotide sequence similarity being to an American virulent strain of fowlpox virus (99.3\%), followed by PEPV (76.6\%), FGPV (75.0\%), and FeP2 (73.1\%). The AT content of the ALPV2 genome was 69.1\%, which was consistent with previously reported avipoxviruses. Given the phylogenetic relationship of ALPV2 (Figures 3 and 4; Supplementary Figures S1 and S2), we propose that this virus, in contrast to ALPV [29], originated from a common ancestor that deviated from a fowlpox virus-like progenitor. Notably, there were significant differences observed between the ALPV2 and ALPV genomes (regarding nucleotide identity, genome length and number of ORFs (Table 2)), confirming that two distinct avipoxviruses were present in juvenile northern royal albatrosses sampled on the Otago Peninsula (South Island of New Zealand) in March 1997.

Interestingly, the phylogenetic relationship of ALPV2 using concatenated protein sequences encoded by the chosen poxvirus core genes (Figure 3), and partial nucleotide sequences of DNA polymerase and P4b genes (Figure 4), demonstrate that the newly assembled albatrosspox virus genome is representative of a sub-clade A1 avipoxvirus. In support of our findings, nearly identical partial nucleotide sequences of fowlpox viruses were isolated from other non-chicken avian species including blue-eared pheasant (Crossoptilon auritum) in Hawaii [59] and a Psittaciformes (superb parrot, Polytelis swainsonii) originating from Chile [59], which are also positioned in the same A1 sub-clade. In addition, an atypical fowlpox virus was also reported from a fatally ill rhinoceros in 1969 [28]; however, genetic characterization of this virus has not been reported. Two recent studies of avipoxvirus-like 
viruses provide examples of viruses able to infect non-avian hosts: cheloniid poxvirus 1 (ChePV-1) and teiidaepox virus 1 (TePV-1), which have been linked with infections in green sea turtle and crocodile tegu $[26,27]$. Our findings suggest an unusual transmission event may have occurred, resulting in lesions, representing either a "dead-end" event and/or that fowlpox-like viruses may have a wider host range with the ability to cross chicken-host barriers. Characterization of additional avipoxviruses isolated from these endangered albatross species may enable the likelihood and importance of cross species transmission of fowlpox and fowlpox-like viruses to be determined.

It is not possible to explain the host-pathogen dynamics of ALPV2 from this case alone, but it is apparent that northern royal albatrosses and other avian species share an ecological habitat. Northern royal albatrosses are typically solitary foragers, however they may gather at food sources at sea. Most of their food is thought to be obtained by feeding on dead or dying prey from the surface and by scavanging fish, rubbish and bait discarded from commercial fishing boats. This may indicate a possible scenario for virus transmission that requires further investigation. Another potential route of virus transmission is mechanical, where biting arthropods are assumed to play a part in the spread of avipoxviruses within wild bird populations. Ticks, fleas [60], hippoboscid flies [61], and mosquitos [19,62] may all play a role as mechanical vectors. Northern royal albatrosses also congregate at breeding colonies where transmission of avipoxviruses by insect vectors is likely to occur.

Avipoxviruses have been reported to infect other albatross species, including a critically endangered Waved Albatross (Phoebastria irrorata) [63] and Laysan Albatross (Phoebastria immutabilis) [21]. The severity of avipoxvirus infections is variable and infrequently fatal, although secondary bacterial and fungal infections may subsequently occur and cause mortality [23]. Nevertheless, the pathogenic effects of avipoxvirus infections in seabirds are not adequately understood, and the longer-term consequences in susceptible populations remain to be determined. The genetic information provided in this study will facilitate improved understanding of the evolution of poxviruses in this avian species, thus contributing to the development of improved management and conservation strategies for the endangered northern royal albatross.

\section{Conclusions}

We have reported the genomic characterization of a second novel avipoxvirus, tentatively designated ALPV2, isolated from an endangered northern royal albatross on the Otago Peninsula, New Zealand, and provide evidence that this infection resulted from a possible host switch event. The ALPV2 genome was similar to those of other avipoxviruses and likely originated from a common ancestor that deviated from a fowlpox virus-like progenitor. This finding has increased our knowledge of the pathogen diversity within northern royal albatrosses in New Zealand. However, additional investigations will be required to better understand relevant host-pathogen dynamics including routes of transmission and factors leading to infection, associated pathology and disease prevalence.

Supplementary Materials: The following supporting information can be downloaded at: https:// www.mdpi.com/article/10.3390/v14020302/s1, Figure S1: Maximum likelihood (ML) phylogenetic tree from partial nucleotide sequences of the DNA polymerase gene of selected avipoxviruses; Figure S2: Maximum likelihood (ML) phylogenetic tree from partial nucleotide sequences of the P4b gene of selected avipoxviruses; Table S1: Albatrosspox virus 2 (ALPV2) genome annotations and comparative analysis of ORFs.

Author Contributions: Conceptualization, S.S., T.R.B. and D.B.B.; Formal analysis, S.S.; Funding acquisition, S.S. and D.B.B.; Investigation, S.S. and D.B.B.; Methodology, S.S. and D.B.B.; Writingoriginal draft, S.S.; Writing-review and editing, S.S., T.R.B. and D.B.B. All authors have read and agreed to the published version of the manuscript.

Funding: Dr. Sarker is the recipient of an Australian Research Council Discovery Early Career Researcher Award (grant number DE200100367) funded by the Australian government. We also 
gratefully acknowledge the funding contributed by the Australian Biosecurity CRC for Emerging Infectious Disease in support of this work.

Institutional Review Board Statement: The material used in this study was provided by New Zealand Ministry for Primary Industries, Animal Health Laboratory, which was submitted for diagnostic purposes. The findings from the diagnostic material were to be used in a publication, and no specific ethical approval was required.

Informed Consent Statement: Not applicable.

Data Availability Statement: The complete genome sequence and associated datasets generated during this study were deposited in GenBank under the accession number OK348853.

Acknowledgments: The authors are thankful to the New Zealand Ministry for Primary Industries, Animal Health Laboratory, for providing the skin lesion from which ALPV2 was isolated.

Conflicts of Interest: The authors declare no conflict of interest.

\section{References}

1. Croxall, J.P.; Butchart, S.H.M.; Lascelles, B.E.N.; Stattersfield, A.J.; Sullivan, B.E.N.; Symes, A.; Taylor, P. Seabird conservation status, threats and priority actions: A global assessment. Bird Conserv. Int. 2012, 22, 1-34. [CrossRef]

2. Croxall, J.P.; Gales, R. An Assessment of the Conservation Status of Albatrosses. In Albatross Biology and Conservation; Robertson, G., Gales, R., Eds.; Surrey Beatty \& Sons: Chipping Norton, UK, 1998; pp. 46-65.

3. Cooper, J.; Baker, G.B.; Double, M.C.; Gales, R.; Papworth, W.; Tasker, M.L.; Waugh, S.M. The agreement on the conservation of albatrosses and petrels: Rationale, history, progress and the way forward. Mar. Ornithol. 2006, 34, 1-5.

4. Marcela, M.; Uhart, L.G.; Flavio, Q. Review of diseases (pathogen isolation, direct recovery and antibodies) in albatrosses and large petrels worldwide. Bird Conserv. Int. 2018, 28, 169-196.

5. BirdLife, I. Diomedea sanfordi. The IUCN Red List of Threatened Species 2018: E.T22728323A132656392. Available online: https:/ / doi.org/10.2305/IUCN.UK.2018-2.RLTS.T22728323A132656392.en (accessed on 30 January 2021).

6. Sugishita, J. Northern Royal Albatross. New Zealand Birds Online. 2013. Miskelly, C.M., Ed.; Available online: http://www. nzbirdsonline.org.nz/species/northern-royal-albatross (accessed on 30 January 2021).

7. Halpern, B.S.; Walbridge, S.; Selkoe, K.A.; Kappel, C.V.; Micheli, F.; D’Agrosa, C.; Bruno, J.F.; Casey, K.S.; Ebert, C.; Fox, H.E.; et al. A global map of human impact on marine ecosystems. Science 2008, 319, 948-952. [CrossRef] [PubMed]

8. Tuck, G.N.; Polacheck, T.; Croxall, J.P.; Weimerskirch, H. Modelling the impact of fishery by-catches on albatross populations. J. Appl. Ecol. 2001, 38, 1182-1196. [CrossRef]

9. Baker, G.B.; Gales, R.; Hamilton, S.; Wilkinson, V. Albatrosses and petrels in Australia: A review of their conservation and management. Emu-Austral Ornithol. 2002, 102, 71-97. [CrossRef]

10. Lewison, R.L.; Crowder, L.B.; Read, A.J.; Freeman, S.A. Understanding impacts of fisheries bycatch on marine megafauna. Trends Ecol. Evol. 2004, 19, 598-604. [CrossRef]

11. Rolland, V.; Barbraud, C.; Weimerskirch, H. Assessing the impact of fisheries, climate and disease on the dynamics of the Indian yellow-nosed Albatross. Biol. Conserv. 2009, 142, 1084-1095. [CrossRef]

12. Phillips, R.A.; Gales, R.; Baker, G.B.; Double, M.C.; Favero, M.; Quintana, F.; Tasker, M.L.; Weimerskirch, H.; Uhart, M.; Wolfaardt, A. The conservation status and priorities for albatrosses and large petrels. Biol. Conserv. 2016, 201, 169-183. [CrossRef]

13. Department of Sustainability, Environment, Water, Population and Communities. Background Paper, Population Status and Threats to Albatrosses and Giant Petrels Listed as Threatened under the Environment Protection and Biodiversity Conservation Act 1999. 2011. Available online: https://www.environment.gov.au/resource/background-paper-population-status-and-threatsalbatrosses-and-giant-petrels-listed (accessed on 29 January 2021).

14. Illera, J.C.; Emerson, B.C.; Richardson, D.S. Genetic characterization, distribution and prevalence of avian pox and avian malaria in the Berthelot's pipit (Anthus berthelotii) in Macaronesia. Parasitol. Res. 2008, 103, 1435-1443. [CrossRef] [PubMed]

15. Lecis, R.; Secci, F.; Antuofermo, E.; Nuvoli, S.; Scagliarini, A.; Pittau, M.; Alberti, A. Multiple gene typing and phylogeny of avipoxvirus associated with cutaneous lesions in a stone curlew. Vet. Res. Commun. 2017, 4, 77-83. [CrossRef] [PubMed]

16. Woolaver, L.G.; Nichols, R.K.; Morton, E.S.; Stutchbury, B.J.M. Population genetics and relatedness in a critically endangered island raptor, Ridgway's Hawk Buteo ridgwayi. Conserv. Genet. 2013, 14, 559-571. [CrossRef]

17. Thiel, T.; Whiteman, N.K.; Tirape, A.; Baquero, M.I.; Cedeno, V.; Walsh, T.; Uzcategui, G.J.; Parker, P.G. Characterization of canarypox-like viruses infecting endemic birds in the Galapagos Islands. J. Wildl. Dis. 2005, 41, 342-353. [CrossRef]

18. Sarker, S.; Athukorala, A.; Bowden, T.R.; Boyle, D.B. Genomic Characterisation of a Novel Avipoxvirus Isolated from an Endangered Yellow-Eyed Penguin (Megadyptes antipodes). Viruses 2021, 13, 194. [CrossRef] [PubMed]

19. Van Riper, C.; van Riper, S.G.; Hansen, W.R. Epizootiology and Effect of Avian Pox on Hawaiian Forest Birds. Auk 2002, 119, 929-942.

20. Parker, P.G.; Buckles, E.L.; Farrington, H.; Petren, K.; Whiteman, N.K.; Ricklefs, R.E.; Bollmer, J.L.; Jiménez-Uzcátegui, G. 110 years of Avipoxvirus in the Galapagos Islands. PLoS ONE 2011, 6, e15989. [CrossRef] [PubMed] 
21. Young, L.C.; VanderWerf, E.A. Prevalence of avian pox virus and effect on the fledging success of Laysan Albatross. J. Field Ornithol. 2008, 79, 93-98. [CrossRef]

22. Bolte, A.L.; Meurer, J.; Kaleta, E.F. Avian host spectrum of avipoxviruses. Avian Pathol. 1999, 28, 415-432. [CrossRef] [PubMed]

23. Van Riper, C.; Forrester, D.J. Avian Pox. In Infectious Diseases of Wild Birds; Thomas, N.J., Hunter, D.B., Atkinson, C.T., Eds.; Wiley Blackwell Publishing: Oxford, UK, 2007; pp. 131-176.

24. Carulei, O.; Douglass, N.; Williamson, A.-L. Comparative analysis of avian poxvirus genomes, including a novel poxvirus from lesser flamingos (Phoenicopterus minor), highlights the lack of conservation of the central region. BMC Genom. 2017, 18, 947. [CrossRef] [PubMed]

25. Williams, R.A.J.; Truchado, D.A.; Benitez, L. A Review on the Prevalence of Poxvirus Disease in Free-Living and Captive Wild Birds. Microbiol. Res. 2021, 12, 403-418. [CrossRef]

26. Sarker, S.; Hannon, C.; Athukorala, A.; Bielefeldt-Ohmann, H. Emergence of a Novel Pathogenic Poxvirus Infection in the Endangered Green Sea Turtle (Chelonia mydas) Highlights a Key Threatening Process. Viruses 2021, 13, 219. [CrossRef] [PubMed]

27. Seitz, K.; Kübber-Heiss, A.; Auer, A.; Dinhopl, N.; Posautz, A.; Mötz, M.; Kiesler, A.; Hochleithner, C.; Hochleithner, M.; Springler, G.; et al. Discovery of a phylogenetically distinct poxvirus in diseased Crocodilurus amazonicus (family Teiidae). Arch. Virol. 2021, 166, 1183-1191. [CrossRef] [PubMed]

28. Mayr, A.; Mahnel, H. Characterization of a fowlpox virus isolated from a rhinoceros. Arch. Gesamte Virusforsch. 1970, 31, 51-60. [CrossRef] [PubMed]

29. Sarker, S.; Athukorala, A.; Nyandowe, T.; Bowden, T.R.; Boyle, D.B. Genomic Characterisation of a Novel Avipoxvirus Isolated from an Endangered Northern Royal Albatross (Diomedea sanfordi). Pathogens 2021, 10, 575. [CrossRef] [PubMed]

30. Sarker, S.; Das, S.; Lavers, J.L.; Hutton, I.; Helbig, K.; Imbery, J.; Upton, C.; Raidal, S.R. Genomic characterization of two novel pathogenic avipoxviruses isolated from pacific shearwaters (Ardenna spp.). BMC Genom. 2017, 18, 298. [CrossRef] [PubMed]

31. Sarker, S.; Roberts, H.K.; Tidd, N.; Ault, S.; Ladmore, G.; Peters, A.; Forwood, J.K.; Helbig, K.; Raidal, S.R. Molecular and microscopic characterization of a novel Eastern Grey Kangaroopox Virus genome directly from a clinical sample. Sci. Rep. 2017, 7, 16472. [CrossRef] [PubMed]

32. Sarker, S.; Batinovic, S.; Talukder, S.; Das, S.; Park, F.; Petrovski, S.; Forwood, J.K.; Helbig, K.J.; Raidal, S.R. Molecular characterisation of a novel pathogenic avipoxvirus from the Australian magpie (Gymnorhina tibicen). Virology 2020, 540, 1-6. [CrossRef] [PubMed]

33. Sarker, S.; Isberg, S.R.; Athukorala, A.; Mathew, R.; Capati, N.; Haque, M.H.; Helbig, K.J. Characterization of a Complete Genome Sequence of Molluscum Contagiosum Virus from an Adult Woman in Australia. Microbiol. Resour. Announc. 2021, 10, e00939-20. [CrossRef] [PubMed]

34. Altschul, S.F.; Gish, W.; Miller, W.; Myers, E.W.; Lipman, D.J. Basic local alignment search tool. J. Mol. Biol. 1990, 215 , 403-410. [CrossRef]

35. Krogh, A.; Larsson, B.; von Heijne, G.; Sonnhammer, E.L. Predicting transmembrane protein topology with a hidden Markov model: Application to complete genomes. J. Mol. Biol. 2001, 305, 567-580. [CrossRef] [PubMed]

36. Hofmann, K.; Stoffel, W. TMBASE-A database of membrane spanning protein segments. Biol. Chem. Hoppe-Seyler 1993, 374,166

37. Zimmermann, L.; Stephens, A.; Nam, S.Z.; Rau, D.; Kubler, J.; Lozajic, M.; Gabler, F.; Soding, J.; Lupas, A.N.; Alva, V. A Completely Reimplemented MPI Bioinformatics Toolkit with a New HHpred Server at its Core. J. Mol. Biol. 2018, 430, 2237-2243. [CrossRef]

38. Kelley, L.A.; Mezulis, S.; Yates, C.M.; Wass, M.N.; Sternberg, M.J.E. The Phyre2 web portal for protein modeling, prediction and analysis. Nat. Protoc. 2015, 10, 845. [CrossRef]

39. Waterhouse, A.; Bertoni, M.; Bienert, S.; Studer, G.; Tauriello, G.; Gumienny, R.; Heer, F.T.; de Beer, T.A.P.; Rempfer, C.; Bordoli, L.; et al. SWISS-MODEL: Homology modelling of protein structures and complexes. Nucleic Acids Res. 2018, 46, W296-W303. [CrossRef] [PubMed]

40. Maizel, J.V., Jr.; Lenk, R.P. Enhanced graphic matrix analysis of nucleic acid and protein sequences. Proc. Natl. Acad. Sci. USA 1981, 78, 7665-7669. [CrossRef]

41. Sarker, S.; Athukorala, A.; Raidal, S.R. Molecular characterisation of a novel pathogenic avipoxvirus from an Australian passerine bird, mudlark (Grallina cyanoleuca). Virology 2021, 554, 66-74. [CrossRef] [PubMed]

42. Katoh, K.; Standley, D.M. MAFFT Multiple Sequence Alignment Software Version 7: Improvements in Performance and Usability. Mol. Biol. Evol. 2013, 30, 772-780. [CrossRef] [PubMed]

43. Tulman, E.R.; Afonso, C.L.; Lu, Z.; Zsak, L.; Kutish, G.F.; Rock, D.L. The Genome of Canarypox Virus. J. Virol. 2004, 78, $353-366$. [CrossRef]

44. Le Net, R.; Provost, C.; Lalonde, C.; Régimbald, L.; Vézina, F.; Gagnon, C.A.; Lair, S. Whole genome sequencing of an avipoxvirus associated with infections in a group of aviary-housed snow buntings (Plectrophenax nivalis). J. Zoo Wildl. Med. 2020, 50, 803-812 [CrossRef]

45. Afonso, C.L.; Tulman, E.R.; Lu, Z.; Zsak, L.; Kutish, G.F.; Rock, D.L. The genome of fowlpox virus. J. Virol. 2000, 74, 3815-3831. [CrossRef]

46. Joshi, L.R.; Bauermann, F.V.; Hain, K.S.; Kutish, G.F.; Armién, A.G.; Lehman, C.P.; Neiger, R.; Afonso, C.L.; Tripathy, D.N.; Diel, D.G. Detection of Fowlpox virus carrying distinct genome segments of Reticuloendotheliosis virus. Virus Res. 2019, 260, 53-59. [CrossRef] 
47. Croville, G.; Le Loc'h, G.; Zanchetta, C.; Manno, M.; Camus-Bouclainville, C.; Klopp, C.; Delverdier, M.; Lucas, M.-N.; Donnadieu, C.; Delpont, M.; et al. Rapid whole-genome based typing and surveillance of avipoxviruses using nanopore sequencing. J. Virol. Methods 2018, 261, 34-39. [CrossRef] [PubMed]

48. Sarker, S.; Athukorala, A.; Bowden, T.R.; Boyle, D.B. Characterisation of an Australian fowlpox virus carrying a near-full-length provirus of reticuloendotheliosis virus. Arch. Virol. 2021, 166, 1485-1488. [CrossRef] [PubMed]

49. Asif, K.; O’Rourke, D.; Legione, A.R.; Shil, P.; Marenda, M.S.; Noormohammadi, A.H. Whole-genome based strain identification of fowlpox virus directly from cutaneous tissue and propagated virus. PLoS ONE 2021, 16, e0261122. [CrossRef]

50. Sarker, S.; Bowden, T.R.; Boyle, D.B. Genomic characterisation of a novel avipoxvirus, magpiepox virus 2, from an Australian magpie (Gymnorhina tibicen terraereginae). Virology 2021, 562, 121-127. [CrossRef]

51. Offerman, K.; Carulei, O.; van der Walt, A.P.; Douglass, N.; Williamson, A.-L. The complete genome sequences of poxviruses isolated from a penguin and a pigeon in South Africa and comparison to other sequenced avipoxviruses. BMC Genom. 2014, 15, 463. [CrossRef]

52. Sarker, S.; Isberg, R.S.; Moran, L.J.; Araujo, D.R.; Elliott, N.; Melville, L.; Beddoe, T.; Helbig, J.K. Crocodilepox Virus Evolutionary Genomics Supports Observed Poxvirus Infection Dynamics on Saltwater Crocodile (Crocodylus porosus). Viruses 2019, 11, 1116. [CrossRef] [PubMed]

53. Sarker, S.; Isberg, S.R.; Milic, N.L.; Lock, P.; Helbig, K.J. Molecular characterization of the first saltwater crocodilepox virus genome sequences from the world's largest living member of the Crocodylia. Sci. Rep. 2018, 8, 5623. [CrossRef]

54. Banyai, K.; Palya, V.; Denes, B.; Glavits, R.; Ivanics, E.; Horvath, B.; Farkas, S.L.; Marton, S.; Balint, A.; Gyuranecz, M.; et al. Unique genomic organization of a novel Avipoxvirus detected in turkey (Meleagris gallopavo). Infect. Genet. Evol. 2015, 35, 221-229. [CrossRef] [PubMed]

55. Laidlaw, S.M.; Skinner, M.A. Comparison of the genome sequence of FP9, an attenuated, tissue culture-adapted European strain of Fowlpox virus, with those of virulent American and European viruses. J. Gen. Virol. 2004, 85, 305-322. [CrossRef] [PubMed]

56. Pollitt, E.; Skinner, M.A.; Heaphy, S. Nucleotide sequence of the $4.3 \mathrm{kbp}$ BamHI-N fragment of fowlpox virus FP9. Virus Genes 1998, 17, 5-9. [CrossRef]

57. Upton, C.; Slack, S.; Hunter, A.L.; Ehlers, A.; Roper, R.L. Poxvirus Orthologous Clusters: Toward Defining the Minimum Essential Poxvirus Genome. J. Virol. 2003, 77, 7590-7600. [CrossRef] [PubMed]

58. Lefkowitz, E.J.; Wang, C.; Upton, C. Poxviruses: Past, present and future. Virus Res. 2006, 117, 105-118. [CrossRef] [PubMed]

59. Gyuranecz, M.; Foster, J.T.; Dán, Á.; Ip, H.S.; Egstad, K.F.; Parker, P.G.; Higashiguchi, J.M.; Skinner, M.A.; Höfle, U.; Kreizinger, Z.; et al. Worldwide Phylogenetic Relationship of Avian Poxviruses. J. Virol. 2013, 87, 4938-4951. [CrossRef]

60. Kane, O.J.; Uhart, M.M.; Rago, V.; Pereda, A.J.; Smith, J.R.; Van Buren, A.; Clark, J.A.; Boersma, P.D. Avian pox in Magellanic Penguins (Spheniscus magellanicus). J. Wildl. Dis. 2012, 48, 790-794. [CrossRef] [PubMed]

61. Warner, R.E. The Role of Introduced Diseases in the Extinction of the Endemic Hawaiian Avifauna. Condor 1968, 70, 101-120. [CrossRef]

62. Annuar, B.O.; Mackenzie, J.S.; Lalor, P.A. Isolation and characterization of avipoxviruses from wild birds in Western Australia. Arch. Virol. 1983, 76, 217-229. [CrossRef] [PubMed]

63. Tompkins, E.M.; Anderson, D.J.; Pabilonia, K.L.; Huyvaert, K.P. Avian Pox Discovered in the Critically Endangered Waved Albatross (Phoebastria irrorata) from the Galápagos Islands, Ecuador. J. Wildl. Dis. 2017, 53, 891-895. [CrossRef] 